\title{
Projeto Porto Nacional (Tocantins): uma proposta de atuação em saúde mental na comunidade
}

\author{
Adriane Bacellar Duarte Lima ${ }^{1}$ \\ Paulo Jannuzzi Cunha ${ }^{2}$ \\ Paulo Germano Marmorato ${ }^{3}$ \\ Leon de Souza Garcia ${ }^{4}$ \\ Francisco Lotufo Neto ${ }^{5}$
}

Recebido: 7/3/2003 Aceito: 7/5/2003

\section{Resumo}

Este projeto relata a implantação de um serviço de saúde mental por meio de parceria do Instituto de Psiquiatria do Hospital das Clínicas da Faculdade de Medicina da Universidade de São Paulo com a Prefeitura do Município de Porto Nacional, Estado de Tocantins. Na região havia poucos serviços de saúde mental, praticamente com ausência de assistência num raio de $500 \mathrm{~km}$.

Foi realizado por equipe formada por médicos residentes, psicólogos e aprimorandos de Psicologia, que auxiliaram na implantação de um Núcleo de Atenção Psicossocial (NAPS) e de diversos serviços à comunidade local. Os benefícios foram inúmeros à comunidade e aos participantes.

Unitermos: Saúde mental; Implantação de serviço; Voluntariado; Núcleo de atenção psicossocial; NAPS; CAPS.

\section{ABSTRACT}

The beginning and organization of a Mental Health Service through cooperation between The Institute and Department of Psychiatry - University of São Paulo and the city of Porto Nacional, Tocantins, Central Brazil

There was no systematic mental health assistance in this region. The project was developed by psychiatric

residents, psychologists and psychology trainees who through volunteer work helped to organize a mental health service and assistance to the community. Benefits for the community and the volunteer workers were discussed.

Keywords: Mental health; New service organization; Volunteer work.

\section{Introdução}

Segundo a Organização Mundial da Saúde (OMS), uma melhora nos cuidados com as pessoas que sofrem de transtornos mentais depende de uma melhor educação dos trabalhadores em saúde, do público em geral e de um compromisso mais intensivo dos governos quanto ao desenvolvimento de serviços de atendimento aos doentes mentais e às suas comunidades (OMS, 1997). A Saúde Mental na Comunidade é um movimento relativamente novo, que aproxima do cotidiano das pessoas, principalmente nos bairros e instituições populares, onde a grande parcela da população vive, organiza-se e cria seus canais de expressão (Andery, 1984).

Com base nesse modelo, que visa à integração da assistência em saúde mental aos recursos de uma determinada comunidade, foi estabelecido um convênio entre o Instituto de Psiquiatria do Hospital das Clínicas da Faculdade de Medicina da Universidade de São Paulo (IPqHCFMUSP) e a Prefeitura do Município de Porto Nacional (TO), em colaboração com a organização nãogovernamental denominada Comunidade de Saúde, Desenvolvimento e Educação (Comsaúde) da cidade.

\footnotetext{
Trabalho apresentado na I Mostra Nacional de Práticas em Psicologia. Conselho Federal de Psicologia (CFP): São Paulo, 2000; e no XXVIII Congresso Interamericano de Psicologia. Sociedade Interamericana de Psicologia (SIP): Chile, 2001.

Psicóloga do Serviço de Psicologia do Instituto de Psiquiatria do Hospital das Clínicas da Faculdade de Medicina da USP (IPqHCFMUSP).

Psicólogo, Especialista em Neuropsicologia pelo IPqHCFMUSP e Mestrando pela Faculdade de Medicina da USP.

Médico Psiquiatra, Preceptor da Residência Médica do IPqHCFMUSP.

Médico Psiquiatra. Assistente do IPqHCFMUSP.

Livre-Docente do Departamento de Psiquiatria da Faculdade de Medicina da Universidade de São Paulo.
} 
Tal iniciativa surgiu no final de 1999, a partir da verificação de uma carência de serviços adequados na área de saúde mental na cidade de Porto Nacional (TO), limitados a um NAPS (Núcleo de Atenção Psicossocial) ainda incipiente. Não havia ainda um Ambulatório de Saúde Mental estruturado na cidade; em um raio de $500 \mathrm{~km}$, sequer havia assistência em Saúde Mental. O hospital para internações ficava a $650 \mathrm{~km}$.

Para um trabalho dessa amplitude, a equipe deve compreender a estrutura da comunidade na qual está inserida, sua organização, seus problemas, as diferentes formas como seus membros vivem, suas crenças, valores e normas que a regem, suas necessidades e a maneira de satisfazê-las (Bleger, 1984). Essa compreensão deve se estender a todos os profissionais, não somente àqueles que fazem parte da equipe multidisciplinar, mas também àqueles que trabalham diretamente com a população, tais como professores, agentes comunitários de saúde, grupos religiosos e autoridades.

\section{A cidade}

Porto Nacional localiza-se na região Norte do país, Estado de Tocantins, na Amazônia Legal, a 64 km de distância da capital, Palmas. Possui cerca de 43 mil habitantes. Foi um pólo econômico importante em decorrência da presença de jazidas de ouro na região, esgotadas com a exploração ocorrida no século XIX. Atualmente, sua principal atividade econômica é a agricultura. A região já passou por vários períodos migratórios, e, em virtude disso, sua população é formada por pessoas de praticamente todas as regiões do país. Dessa forma, Porto Nacional encontra-se com sua identidade cultural ainda em formação, sendo possível observar uma grande variedade de costumes e modos de vida dentro da população.

\section{Objetivos}

O objetivo do presente trabalho foi desenvolver um projeto de implantação de serviços em saúde mental comunitária que contemplasse os aspectos básicos de atendimento e prevenção, com integração à rede local e aos recursos comunitários disponíveis. Buscou-se também estimular a participação da população e dos profissionais na elaboração de estratégias de atendimento, favorecendo a conscientização e o exercício da cidadania.

Outro objetivo importante para os profissionais envolvidos foi promover o conhecimento, a familiarização com os programas de saúde mental na rede pública e o treinamento de pessoal, bem como participar do funcionamento de núcleos/centros de atenção psicossocial (NAPS/CAPS), serviços estes cada vez mais presentes na realidade nacional.

Especificamente em relação à formação dos residentes, podemos citar: 1) ampliação dos recursos técnicos e emocionais para atender populações culturalmente diversas em termos de linguagem, hábitos e valores; 2) consolidação da identidade e responsabilidade do residente, que passa a ter um papel singular na equipe do serviço; 3 ) proporcionar oportunidades para elaborar soluções criativas para os problemas, muitas vezes não previsíveis, que surgem.

\section{A equipe}

A equipe foi formada por médicos psiquiatras, psicólogos, residentes de segundo ano em Psiquiatria, e aprimorandos na área de Psicologia. A participação foi voluntária, aberta aos interessados nas atividades propostas. Cada profissional permaneceu durante um mês em regime de dedicação integral e recebia supervisões a distância, por telefone ou Internet. Enquanto isso, em São Paulo, a equipe reunia-se semanalmente, para discutir não só os casos clínicos, mas o trabalho como um todo.

O convênio com a prefeitura viabilizou as passagens de ônibus e a hospedagem local.

\section{Planejamento do trabalho}

O projeto de trabalho dividiu-se em quatro fases principais, descritas a seguir.

\section{$1^{\text {a }}$ fase: detecção da demanda e atendimento emergencial.}

Foram realizadas reuniões, ainda em São Paulo, para traçar o perfil do trabalho. Ajustados os detalhes do convênio, efetuaram-se observações e análises in loco, com o objetivo de detectar a demanda da comunidade, verificando as possibilidades de atendimento. Tiveram ênfase um trabalho clínico psiquiátrico e atendimentos psicológicos emergenciais, caracterizados por atendimentos breves de orientação e apoio, para a população que procurava espontaneamente o NAPS.

$2^{\text {a }}$ fase: treinamento de profissionais locais e implantação dos serviços em saúde mental.

Verificou-se a necessidade de se ampliar o trabalho. Enquanto os atendimentos psicológicos e psiquiátricos continuavam, grupos interdisciplinares específicos foram implantados. O perfil do NAPS foi se transformando: criou-se o Grupo de Adolescentes, que estavam 
em situação de risco, encaminhados pela juíza municipal e por lideranças comunitárias. Constituiu-se também o Grupo de Pais, formado por genitores que se queixavam de dificuldade em lidar com os filhos adolescentes. Iniciou-se o Grupo de Mulheres, formado por vítimas de violência doméstica e/ou sexual, e ainda, o Grupo de Adultos, com a finalidade de atender os pacientes que apresentavam queixas psicossomáticas. Em decorrência, houve o escoamento dos atendimentos individuais de emergência para os grupos. Além do trabalho no NAPS, expandiram-se as atividades para os postos de saúde do município, formando grupos destinados à atenção primária em saúde mental. Ainda nessa fase, cursos de caráter interdisciplinar com os objetivos de capacitação/ treinamento foram planejados e executados, atingindo profissionais locais, tais como médicos, enfermeiros, auxiliares de enfermagem, professores e agentes comunitários de saúde. Os cursos abrangeram diversos temas, tais como noções em saúde mental, diagnóstico, tratamento e abordagem de pacientes enfermos, entre outros, que variavam de acordo com as necessidades de cada grupo atendido. Implantou-se ainda o sistema de visitas domiciliares, através do qual profissionais do NAPS, juntamente com os agentes comunitários de saúde (Programa de Saúde da Família - PSF), podiam deslocarse até as casas dos pacientes que por algum motivo não poderiam chegar até o NAPS.

\section{$3^{\text {a }}$ fase: viabilização da continuidade do trabalho.}

$\mathrm{Na}$ terceira fase, o objetivo principal se expandiu. Além de todas as atividades anteriores terem permanecido, passou-se a buscar também a viabilização da continuidade do trabalho, por meio da contratação de ao menos um profissional, especialmente da área da Psicologia. Este assunto foi tratado em reuniões semanais com o secretário de saúde do município.

\section{$4^{\mathrm{a}}$ fase: avaliação e reprogramação das atividades.}

Uma psicóloga foi contratada, encerrando a terceira fase e dando continuidade ao trabalho realizado pela equipe. A quarta fase foi baseada na avaliação sistematizada dos trabalhos desenvolvidos até então. Neste momento, a equipe de psicólogos concluiu seus objetivos, mas o trabalho desenvolvido pela equipe de médicos residentes continuou.

\section{A dimensão do trabalho}

A fim de que se possa ter uma abrangência do trabalho desenvolvido, no período entre janeiro a julho de 2000, foram realizados 369 atendimentos psicológicos individuais; 93 atendimentos familiares; 20 visitas domiciliares; 11 atendimentos grupais; 16 grupos de prevenção e orientação psicológica, perfazendo um total de 402 participantes, além dos atendimentos clínicos psiquiátricos. Quanto à capacitação profissional, ocorreram 22 grupos, com 268 profissionais entre médicos e técnicos da área da saúde.

Atualmente o NAPS conta com cerca de 1.200 pacientes cadastrados, e os diagnósticos mais freqüentemente realizados referem-se a transtornos ansiosos, transtornos afetivos e esquizofrenia. Dados estão sendo coletados sistematicamente para se traçar com mais precisão o perfil da população atendida e de seus quadros clínicos.

\section{A expansão do trabalho para além de Porto Nacional (TO)}

Além da expansão das atividades em nível primário de saúde mental na cidade de Porto Nacional, a equipe atravessou os limites da cidade e realizou trabalhos com duas comunidades indígenas do Estado do Tocantins. Os trabalhos foram solicitados e financiados pela FASAM (Fundação de Assistência ao Sudeste Amazônico) e pela Fundação Nacional de Saúde (FUNASA), contando também com o apoio da Universidade Federal de Goiás (UFG) - campus de Porto Nacional, TO. As comunidades escolhidas para esses trabalhos foram a dos Javaé (reserva situada na Ilha do Bananal, TO) e a dos Xerente (reserva situada na cidade de Tocantínia, TO). Além dos profissionais de Psicologia e Psiquiatria de São Paulo, participaram também do trabalho os acadêmicos de odontologia e medicina da UFG, dando início às atividades de assistência, educação e prevenção nessas comunidades.

$\mathrm{Na}$ área de saúde mental, a principal demanda verificada foi o problema relacionado ao alto índice de alcoolismo nas aldeias. Verificou-se, no entanto, a necessidade de continuidade do trabalho indígena focando não somente as questões do alcoolismo e outros transtornos mentais, mas, principalmente, o resgate de sua identidade cultural dentro do atual contexto social brasileiro, propiciando-lhes instrumentos para compreensão e modificação de sua condição.

\section{A rede atual de saúde mental}

Os residentes continuam realizando atendimento ambulatorial supervisionado no NAPS e na APAE da cidade, interconsultas em hospital geral, visitas domiciliares e auxiliando na organização de grupos psicoeducacionais para pacientes, familiares e profissionais de saúde. Permanecem também as 
atividades de reabilitação e reuniões com toda a equipe e usuários do serviço. Acrescenta-se a este trabalho um levantamento de dados da população e dos atendimentos realizados no NAPS, desde sua formação. Esses dados deverão orientar a realização de futuros projetos de pesquisa durante o convênio.

Hoje, o NAPS funciona de modo autônomo e integrado ao ambulatório de saúde mental, além de contar com uma equipe de profissionais bem preparados e voltados para a questão comunitária, inclusive com um médico psiquiatra.

Acredita-se que o apoio do Programa de Agentes Comunitários de Saúde (PACS) e do Programa de Saúde da Família, desde o início, tem sido muito importante para a continuidade e aprimoramento do trabalho. O serviço se tornou, em pouco tempo, a referência na área de saúde mental para a região.

\section{Conclusões}

Este projeto de intervenção visou trazer uma contribuição da área de saúde mental para o desenvolvimento de uma conscientização a respeito de fatores que integram o complexo processo de saúde e doença mental, no sentido de: 1) possibilitar questionamentos e esclarecimentos acerca da compreensão de saúde e doença mental; 2) propiciar reflexões sobre a importância de se contribuir para a saúde mental numa comunidade; 3) esclarecer qual o papel e a relevância do trabalho dos profissionais na equipe de saúde mental; 4) conscientizar a comunidade e autoridades a respeito da necessidade de se implantar um serviço estruturado e permanente de atendimento às pessoas portadoras de transtornos mentais e à população em geral; e 5) estabelecer uma parceria entre a universidade e o município.

Notou-se que a imersão do profissional numa comunidade culturalmente distinta propiciou, ainda, a necessidade de adaptação à linguagem e aos hábitos locais, diferentemente do que ocorre em geral em um hospital terciário na cidade de São Paulo, como o caso do Instituto de Psiquiatria, em que o paciente deve esforçar-se para se adaptar às condições existentes.

Por meio desse trabalho, verificou-se que é possível construir conhecimentos teóricos e práticos em saúde mental para favorecer a comunidade, incluindo a parcela economicamente menos favorecida e geograficamente distante dos centros urbanos. Além disso, percebeu-se que o trabalho nesta área não deve contemplar apenas o aspecto patológico em si, e sim abordar a doença dentro de um contexto mais amplo, que é o da saúde e o da rede de serviços da comunidade.

A viabilização deste processo somente se dá a partir do momento em que o profissional se propõe a romper as barreiras de uma prática limitada, para reconhecer, apreender e trabalhar a condição humana dentro do contexto político e social com o qual se depara. Mais que isso, é necessária a elaboração e implementação de políticas públicas de saúde eficientes, que estimulem a participação da comunidade e favoreçam tais ações.

\section{Agradecimentos}

A realização deste trabalho só foi possível graças à colaboração de toda a equipe: Cândida Helena Pires de Camargo, Ana Cláudia Feitosa, Fabiana Saffi, Flávia Ribeiro, Gabriela Albuquerque de Noronha, Luciana de Carvalho Monteiro, Luís Fernando Farah Tóffoli, Marília Yakota e residentes do IPqHCFMUSP.

\section{Referências bibliográficas}

Andery, A.A. - Psicologia na comunidade. In: Lane, S. T.; Codo, W. (orgs.) Psicologia Social - O Homem em Movimento. São Paulo, Editora Brasiliense, p. 203-20, 1984.

Bleger, J - Psico-higiene e psicologia institucional. Porto Alegre, Artes Médicas, 1984.

Negrão, A.B; Licinio, J. - Saúde mental na próxima década. Revista USP, 43: 60-9, 1999.

Organização Mundial da Saúde (OMS): Classificação de transtornos mentais e de comportamento da CID-10: referência rápida. Porto Alegre, Artes Médicas, 1997. 